\title{
An assessment of knowledge of Nigerian female undergraduates on obesity as a risk factor for cardiovascular disease in women
}

\author{
Taofeek Oluwole Awotidebe ${ }^{1, ~}$, Rufus Adesoji Adedoyin ${ }^{1}$, Busola Fatoogun ${ }^{1}$, Victor Adeyeye ${ }^{2}$, \\ Chidozie Emmanuel Mbada ${ }^{1}$, Odunayo Theresa Akinola ${ }^{3}$, Olubusola Esther Johnson ${ }^{1}$, \\ Nicole De Wet ${ }^{4}$ \\ ${ }^{1}$ Department of Medical Rehabilitation, College of Health Sciences, Obafemi Awolowo University, Ile - Ife, Nigeria \\ ${ }^{2}$ Care Care Clinic, Obafemi Awolowo University Teaching Hospitals Complex, Ile - Ife, Nigeria \\ ${ }^{3}$ Department of Physiotherapy, Lagos State University Teaching Hospital, Lagos, Nigeria \\ ${ }^{4}$ Department of Demography and Population Studies Programme, School of Social Sciences, University of the Witwatersrand, Johannesburg, \\ South Africa
}

Email address:

tawotidebe@cartafrica.org (T. O. Awotidebe), tidebet@yahoo.com (T. O. Awotidebe)

\section{To cite this article:}

Taofeek Oluwole Awotidebe, Rufus Adesoji Adedoyin, Busola Fatoogun, Victor Adeyeye, Chidozie Emmanuel. Mbada, Odunayo Theresa Akinola, Olubusola Esther Johnson, Nicole De Wet. An Assessment of Knowledge of Nigerian Female Undergraduates on Obesity as a Risk Factor for Cardiovascular Disease in Women. American Journal of Health Research. Special Issue: Supplementary Prescribing in Nigeria: A Needy Concept to Promote Clinical Physiotherapy Practice. Vol. 2, No. 5-1, 2014, pp. 50-55. doi: 10.11648/j.ajhr.s.2014020501.20

\begin{abstract}
There is an increasing predilection to obesity and consequent cardiovascular disease (CVD) among women. This study investigated knowledge of Nigerian female undergraduates on obesity as a risk factor for CVD in women. This crosssectional study recruited 400 female undergraduate students at a tertiary institution in Nigeria. A validated questionnaire was used to assess respondents' knowledge of obesity as a risk factor for CVD. Descriptive statistics of frequency, mean and standard deviation were used to summarize data while inferential statistics of Spearman Rank Correlation was used to determine the relationship between knowledge score and each of age, level of study, and source of information. Alpha level was set at 0.05. Excessive high calorie intake, 322(80.5\%), fatty food intake, 393(98.3\%) and physical inactivity, 360(90.0\%) were the most implicated causative factors for obesity. Three hundred and thirty five $(83.8 \%)$ respondents recognized obesity as a leading cause of CVD. The result of this study also showed that there were no significant relationships between knowledge of obesity as risk factor for CVD and each of age $(r=-0.04 ; p=0.37)$, level of study $(r=0.04 ; p=0.45)$ and source of information $(\mathrm{r}=-0.005 ; \mathrm{p}=0.92)$. We concluded that Nigerian female undergraduates demonstrated average to good knowledge on obesity as risk factor for cardiovascular disease in women. Socio-demographic variables and source of information did not influence Knowledge of obesity as a risk factor for CVD among Nigerian female undergraduates.
\end{abstract}

Keywords: Knowledge, Obesity, Cardiovascular Disease, Female Undergraduate

\section{Introduction}

Rapid urbanization, unhealthy lifestyles and physical inactivity were the most implicated factors in the global prevalence of obesity [1, 2]. Consequently, chronic noncommunicable diseases such as type-2 diabetes, dyslipidemia, hypertension, stroke, heart failure and kidney failure are on the rise $[3,4]$. Of all the chronic non-communicable diseases, Cardiovascular Disease (CVD) had been reported to be the leading cause of morbidity and mortality worldwide accounting for a third of all global death in the last three decades $[5,6]$.

Both obesity and CVD represent major public health problems in Western societies and similar trend have been observed in sub-Saharan African (SSA) countries [7]. The epidemiological transition of chronic non-communicable diseases in SSA is purported to have overtaken the front burner infectious diseases such as HIV/AIDS and tuberculosis $[8,9]$, with significant predilection to the female gender $[7,10]$. More than half of the female population in 
South Africa is obese [11] while in Morocco more than $40 \%$ of the total population is obese with the female gender constituting a greater proportion [12]. Similarly, the WHO report in Nigeria reported a higher prevalence of overweight and obesity among women [13].

Obesity in young female adults is fast becoming an important public health concern in the developed countries [14]. Unfortunately, obesity in young female adults is pervading the SSA at an alarming rate which deserves urgent public health attention and intervention. In addition to the influence of urbanization and westernization on lifestyle changes and physical inactivity in SSA, the upsurge in prevalence of obesity in young women have been associated with use of contraceptives medications, and cultural perception of obesity as a sign of good living and affluence $[15,16]$. Most women from SSA often prefer to achieve physique with large waist and hip. Some women in south west Nigeria engages the abuse of drugs such as periactin which is believed to enhance body fat. Also in south-south Nigeria (the Efik tribe of Calabar), a bride is locked up in the "fattening room" to achieve desired fatness before marriage.

Unfortunately, high prevalence of obesity is a precursor for CVD risk constituting a significant threat to women's health $[17,18]$. Providing education for women on the consequences of obesity has thus become imperative. Epidemiological studies have reported that one of the most effective methods of combating the epidemic rise of diseases is to evaluate the knowledge level of people concerned in order put in place relevant and strategic plans for effective interventions [19, 20]. Therefore, this study investigated knowledge of Nigerian female undergraduates on obesity as a risk factor for CVD in women.

\section{Materials and Methods}

\subsection{Respondents and Study Setting}

Four hundred and twenty (420) female undergraduates of Obafemi Awolowo University (OAU), Ile - Ife, Osun state Nigeria participated in this cross sectional study. The institution comprises the central campus, the student residential area, the staff quarters and a Teaching and Research Farm. The central campus comprises the academic, administrative units and service centers while the student residential area is made up of 10 undergraduate hostels and a postgraduate hall of residence. Many private hostels are situated outside the campus. The female undergraduate students constitute about $42.8 \%$ of the total population of about 35,000 students [21].

\subsection{Inclusion and Exclusion Criteria}

Eligibility for participation in the study included being a female student residing on campus; younger than 30 years of age and no self-reported history of chronic diseases. Eligible female students from the College of Health Sciences and Faculty of Pharmacy were excluded from the study based on the assumption that they might have been exposed to relevant teachings on obesity and CVDs.

A sample size of 384 was obtained for the study based on a formula for studying population size greater than 10,000 by [22]. However, an estimated sample size of 420 was considered in this study in order to accommodate nonresponders and incomplete or invalid responses.

\subsection{Sampling Technique}

A multistage sampling technique was used to recruit respondents from halls of residence on campus. Three out of four female halls of residence were randomly selected. Five out of eight blocks in each hall of residence were randomly selected with every odd numbered room was selected to recruit respondent who met the inclusion criteria.

\subsection{Procedure}

Ethical approval for the study was obtained from the Institute of Public Health (IPH), OAU, Ile - Ife, Nigeria. All respondents gave their written informed consent to participate in the survey. Copies of questionnaire were distributed to the respondents. Information on sociodemographic characteristics such as age, course of study and educational level of study were obtained. The period of survey was between $16.00-21.00$ hours when the respondents could be met in their halls of residence.

\subsection{Instrument}

A structured questionnaire on knowledge of obesity as a risk factor for CVD was used to collect data for this study. Prior to the study, the questionnaire was tested for content validity by a panel of experts which comprised three physical therapists and two exercise physiologists who were experienced in the field of obesity management and cardiopulmonary training. Consequently, items or questions that were ambiguous or extraneous were either modified or expunged. The test-retest reliability of the questionnaire was determined in a pilot study among 30 female undergraduates who were not part of the main study. The internal consistency of the questionnaire was found to be 0.86 on Cronbach's alpha.

The two-section questionnaire obtained information on demographic variables and assessed knowledge of obesity as a risk factor for CVD. There were 30 questions on knowledge of obesity which comprised causes, assessment, epidemiology, and obesity as a risk factor for CVD, management and source of information on obesity. The answering options were "Yes" or "No" or "I don't know". A correct response was assigned score of 2, incorrect response was given a score of 0 and "I do not know" was assigned 1 .

Responses to the questions on knowledge were summed up and the maximum obtainable score was 60 points. Based on summative knowledge score, $25^{\text {th }}, 50^{\text {th }}$ and $75^{\text {th }}$ percentile cut points were used to grade knowledge as poor, fair and good respectively. 


\subsection{Data Management}

Descriptive statistics of frequency, percentage, mean and standard deviation were used to summarize data. Inferential statistics of Spearman Rank Correlation was used to determine the association between respondents' knowledge of obesity as a risk factor for CVD and each of demographic variables and sources of information. Data analysis was performed using STATA-SE version 11.0 of Windows Software (STATA Corp, Texas, USA). Alpha level was set at $\mathrm{p}<0.05$.

\section{Results}

Out of the 420 eligible respondents approached, 400(95.2\%) were valid for analysis. A majority of the respondents, $239(59.8 \%)$ were within the age range of 21-25years while a quarter, 101(25.3\%) were in the fourth year. The source of information on obesity was mostly from the internet $189(47.3 \%)$. Overall knowledge score of obesity as risk factor for CVD showed that almost half, 199(49.8\%) had good knowledge. Obesity was believed to be caused by excessive intake of high calorie food, $322(80.5 \%)$, fatty foods, 393(98.3\%) and physical inactivity, 360(90.0\%) respectively. More than half, 225(56.3\%) knew correct calculation to determine body mass index (BMI) and a majority, 332(83.0\%) knew waist circumference as standard method for assessing abdominal obesity. Overall knowledge of obesity as a risk factor for CVD showed that less than half, 199(49. 8\%) of the respondents had good knowledge (Table 1).

Table 1. Respondents' demographic characteristics, source of information and knowledge of obesity as a risk factor cardiovascular disease

\begin{tabular}{|c|c|c|}
\hline Variables & & $\mathbf{N}(\%)$ \\
\hline \multicolumn{3}{|l|}{ Age } \\
\hline & $16-20$ & $147(36.8)$ \\
\hline & $21-25$ & $239(59.8)$ \\
\hline & $26-30$ & $14(3.5)$ \\
\hline \multicolumn{3}{|c|}{ Year of study } \\
\hline & First & $25(6.3)$ \\
\hline & Second & $39(9.8)$ \\
\hline & Third & $108(27.0)$ \\
\hline & Fourth & $101(25.3)$ \\
\hline & Fifth & $127(31.8)$ \\
\hline \multicolumn{3}{|l|}{ Faculty } \\
\hline & Agriculture & $80(20.0)$ \\
\hline & Art & $92(23.0)$ \\
\hline \multicolumn{3}{|c|}{ Environmental } \\
\hline & Design & $45(11.3)$ \\
\hline & Humanities & $74(18.5)$ \\
\hline & Technology & $38(9.5)$ \\
\hline & Science & $71(17.8)$ \\
\hline \multicolumn{3}{|c|}{ Source of information } \\
\hline & Radio & $60(15.0)$ \\
\hline & Television & $81(20.3)$ \\
\hline & Internet & $209(52.2)$ \\
\hline & Booklet & $21(5.3)$ \\
\hline & Seminar & $19(4.7)$ \\
\hline & Others & $10(2.5)$ \\
\hline \multicolumn{3}{|c|}{ Knowledge score } \\
\hline & Poor & $158(39.5)$ \\
\hline & Fair & $43(10.7)$ \\
\hline & Good & $199(49.8)$ \\
\hline
\end{tabular}

This study showed that majority of the respondents, $325(81.3 \%)$ agreed that obesity is a risk factor for hypertension. A majority, 335(83.8\%) believed obesity could cause heart attack while 124(31.0\%) agreed that obesity could lead to irregular heartbeat. Three hundred and thirty $(82.5 \%)$ believed that increased physical activity could help in the control of obesity. However, less than half, 174(43.5\%) of the respondents agreed that obesity is reaching an epidemic proportion (Table 2). The result of this study also showed that there were no significant relationships between knowledge of obesity as risk factor for CVD and each of age $(\mathrm{r}=-0.04 ; \mathrm{p}=0.37)$, level of study $(\mathrm{r}=0.04 ; \mathrm{p}=0.45)$ and source of information $(\mathrm{r}=-0.005 ; \mathrm{p}=0.92)$ (Table 3$)$.

\section{Discussion}

Obesity is a public health problem worldwide and its prevalence has shown higher propensity among female gender [23]. In the last three decades the prevalence of obesity has been associated with high prevalence of many chronic non-communicable diseases with CVD as the leading causes of morbidity and mortality occurring in more women than men $[23,24]$. This assertion was earlier confirmed by Lowry et al, [25] who submitted that the total sedentary mode of life such as reduced physical activity, longer hour of television viewing and rapid urbanization contribute to high prevalence of obesity among women. Adequate knowledge and awareness of consequence of obesity through public enlightenment programme has been reported to be capable of lessening the prevalence of chronic diseases [26]. There is growing body of evidence that obesity control can reduce the risk of CVD $[2,27]$. In a study conducted by Meisler and St Jeor, [28], it was reported that relatively small amounts of weight loss could lead to significant improvements in blood pressure, blood lipids, and glucose control and insulin levels. They concluded that lifestyle modifications such as increased physical activity and good dietary plan could help in controlling weight gain. Adoption of lifestyle modification to prevent chronic disease requires knowledge acquisition in order to that obesity control can reduce the risk of CVD [2, 27]. In a study conducted by Meisler and St Jeor, [28], it was reported that relatively small amounts of weight loss could lead to significant improvements in blood pressure, blood lipids, and glucose control and insulin levels. They concluded that lifestyle modifications such as increased physical activity and good dietary plan could help in controlling weight gain. Adoption of lifestyle modification to prevent chronic disease requires knowledge acquisition in order to effectively implement action plan for healthy living. Davenport and Prusak [29], defined knowledge as a fluid mix of framed experience, contextual information, values and expert insight that provide a framework for evaluating and incorporating new experiences and information.

This study showed that a little less than half of Nigerian female undergraduates had poor knowledge of obesity as a risk factor for CVD in women, despite the educational status of participants. University students are presumed to have 
higher intellectual capacity and access to information on healthy living from many sources. Education has been reported to significantly influence knowledge and it has also been employed as an intervention to improve knowledge in many health researches. Previous studies showed low level of knowledge among most young populations [30 - 32].

Table 2. Respondents' knowledge of causes, assessment, control and obesity as a risk factor for Cardiovascular Disease (CVD)

\begin{tabular}{|c|c|c|c|}
\hline \multirow{2}{*}{ Variables } & Yes & No & I do not know \\
\hline & n (\%) & n (\%) & n (\%) \\
\hline \multicolumn{4}{|l|}{ Causes of obesity } \\
\hline Can excessive eating lead to obesity? & $295(73.8)$ & $43(10.8)$ & $62(15.5)$ \\
\hline Can high calorie food intake lead to obesity? & $322(80.5)$ & $23(5.8)$ & $55(13.8)$ \\
\hline Can sedentary lifestyle lead to obesity? & $255(63.8)$ & $145(36.2)$ & \\
\hline Can metabolic factors lead to obesity? & $350(87.5)$ & $50(12.5)$ & \\
\hline Can physical inactivity cause obesity? & $360(90.0)$ & $40(10.0)$ & \\
\hline \multicolumn{4}{|l|}{ Assessment of obesity } \\
\hline \multicolumn{4}{|l|}{ Do you know how to assess the followings? } \\
\hline Body Mass Index (BMI) & $225(56.3)$ & $102(25.5)$ & $73(18.2)$ \\
\hline Normal/overweight/obesity & $250(62.5)$ & $135(33.7)$ & $15(3.8)$ \\
\hline Reference points for hip and abdominal circumferences & $332(83.0)$ & $18(4.5)$ & $50(12.5)$ \\
\hline Calculation of Waist to Hip Ratio (WHR) & $188(47.0)$ & $150(37.5)$ & $62(15.5)$ \\
\hline \multicolumn{4}{|l|}{ Obesity as risk factor for CVD } \\
\hline Do you know obesity is a risk factor for CVD? & $260(65.0)$ & $60(15.0)$ & $80(20.0)$ \\
\hline Can obesity cause hypertension? & $325(81.3)$ & $75(18.8)$ & \\
\hline Can obesity lead to stroke? & $297(74.3)$ & $103(25.8)$ & \\
\hline Can obesity cause malfunction of the heart? & $190(47.5)$ & $210(52.5)$ & \\
\hline Can obesity cause blockage of heart vessels? & $311(77.8)$ & $89(22.3)$ & \\
\hline Can obesity cause inflammatory heart disease? & $279(69.8)$ & $121(30.3)$ & \\
\hline Can obesity cause irregular heart beat? & $124(31.0)$ & $276(69.0)$ & \\
\hline Can obesity damage arteries in the body? & $145(36.3)$ & $255(63.8)$ & \\
\hline Can obesity cause weakness of the heart? & $249(62.3)$ & $151(37.8)$ & \\
\hline Can obesity lead blood clot? & $148(37.0)$ & $252(63.0)$ & \\
\hline Can obesity lead blockage of the artery & $151(37.8)$ & $249(62.3)$ & \\
\hline Can obesity lead heart attack? & $335(83.8)$ & $65(16.3)$ & \\
\hline Can obesity cause premature death? & $128(32.0)$ & $272(68.0)$ & \\
\hline Is CVD reaching epidemic proportion? & $174(43.5)$ & $102(25.5)$ & $124(31.0)$ \\
\hline \multicolumn{4}{|l|}{ Prevention of obesity } \\
\hline Increased physical activity & $330(82.5)$ & $23(5.8)$ & $47(11.8)$ \\
\hline
\end{tabular}

Table 3. Correlation between knowledge score of obesity as a risk factor for CVD; and age, level of study and source of information

\begin{tabular}{llll}
\hline \multicolumn{2}{l}{ Knowledge Vs Variables } & r & p-value \\
\hline Score & Age & -0.045 & 0.367 \\
& Level of study & 0.037 & 0.456 \\
& Sources of information & -0.005 & 0.923 \\
\hline
\end{tabular}

Significant at $\mathrm{p}<0.05$

This present study's finding is in agreement with previous reports that knowledge of obesity as a risk factor for CVD was associated with educational attainment among women $[17,18]$. On the contrary, Chen et al 33 [26] found that a majority of Southeast Asian women living in Ohio had poor knowledge of obesity as CVD risk. Holdsworth et al, [17] submitted that a large number of women still need additional education on the role of lifestyle modification in keeping optimal weight. Furthermore, Murphy et al, [34] also submitted that increased awareness of lifestyle modifications such as weight control and regular physical activity could help to reduce the prevalence of CVD among women. The misconception about obesity in many societies perceiving individuals with large body frame size as a sign of affluence may contribute to limiting people's ability to seek knowledge about the importance of maintaining optimal body weight. Furthermore, the findings from the present study show that knowledge of obesity was not significantly related with the respondents' demographic variables and source of information. It could be attributed to similarity in age groups, close interactions and high access to internet use among the respondents.

The finding of this study showed that internet was the most available source of information on knowledge of obesity as a risk factor for CVD among the students. The school-aged young population is the most consistent users of social media and information technology. Therefore, an attempt to improve obesity-related knowledge and cardiovascular health may require active and dedicated use of internet and mobile short messaging system as an educational intervention and health promotion in young adults. The outcome of this study may have limited application to other young adults of similar age groups, conducting the study among students of a University produced a sample of high educational status and 
young age, thus reducing generalizability to other Nigerian samples. (explanation offered)

\section{Conclusion}

Less than half of the female undergraduates at a Nigerian university community had good knowledge of obesity as a risk factor for cardiovascular disease in women. Also, Knowledge of obesity as a risk factor for CVD among Nigerian female undergraduates was not influenced by sociodemographic variables and sources of information. We recommend that there should be adequate education on awareness obesity as a risk factors for CVD

\section{Acknowledgements}

The authors wish to thank the Consortium for Advanced Research Training in Africa (CARTA) for providing technical support. CARTA is jointly led by the African Population and Health Research Center and the University of the Witwatersrand and funded by the Wellcome Trust (UK) (Grant No: 087547/Z/08/Z), the Department for International Development (DfID) under the Development Partnerships in Higher Education (DelPHE), the Carnegie Corporation of New York (Grant No: B 8606), the Ford Foundation (Grant No: 1100-0399), Swedish International Development Corporation Agency - SIDA (grant: 54100029), Google.Org (Grant No: 191994), and MacArthur Foundation Grant No: 10-95915-000-INP.

\section{References}

[1] Eckel RH, York DA, Rossner S, Hubbard V, Caterson I, St Jeor ST, Hayman LL, Mullis RM, Blair SN (2004). American Heart Association. Prevention conference VII: Obesity, a worldwide epidemic related to heart disease and stroke: executive summary. Circulation. 110:2968-2975.

[2] Wahab KW, Sani MU, Yusuf BO, Gbadamosi M, Gbadamosi A and Yandutse MI (2011). Prevalence and determinants of obesity - a cross-sectional study of an adult Northern Nigerian population. `Int Arch Med. 4:10

[3] Flegal KM, Carroll MD, Ogden CL, Johnson CL (2002). Prevalence and trends in obesity among US adults, 1999-2000 J Am Med Assoc. 288: 1723-1727.

[4] Eckel RH, Grundy SM and Zimmet PZ (2005). The metabolic syndrome. Lancet. 365: 1415-1428.

[5] Mathers CD, Lopez AD and Murray CJL (2001). "The Burden of Disease and Mortality by Condition: Data, Methods, and Results for." In Global Burden of Disease and Risk Factors, eds. A. D. Lopez, C. D. Mathers, M. Ezzati, D. T. Jamison, and C. J. L. Murray. New York: Oxford University Pres Murray, C. J., and A.D. Lopez. 1994. Global Comparative Assessments in the Health Sector: Disease Burden, Expenditures, and Intervention Packages. Geneva: World Health Organization.

[6] Gaziano TA (2008). Economic burden and the costeffectiveness of treatment of cardiovascular diseases in Africa. Heart. 94, 140-144.
[7] BeLue R, Okoror TA, Iwelunmor J, Taylor KD, Degboe AN, Agyemang C and Ogedegbe, G. (2009). An overview of cardiovascular risk factor burden in sub-Saharan African countries: a socio-cultural perspective. BMC Globalization and Health. 5, 10.

[8] Reddy K and Yusuf S (1998). Emerging epidemic of cardiovascular disease in developing countries. Circulation. 97(6):596-601.

[9] Omran A (2001). The epidemiologic transition. A theory of the Epidemiology of population change. Bull World Health Organ 79(2):161-170.

[10] World Health Organization (2011). Factsheet no. 311: Obesity and Overweight Geneva.

[11] Stein K (2007).MRC Report-Heart Disease in South Africa; Dept. of Medicine at the medical research council: University of Cape Town \& Chronic Diseases of Lifestyle Unit.

[12] Aldair PO (2005). Obesity in Africa. Natl. Health J. 20(7): 18-22.

[13] World Health Organization (2008). 2008-2013 Action Plan for the Global Strategy for the Prevention and Control of Non communicable Diseases Geneva. www.who.int/.../ActionplanPC-NCD-2008 (Accessed on 18/11/2013).

[14] World Health Organization (2005). Preventing Chronic Disease: A Vital Investment: WHO Global Report Geneva. www.who.int/chp/chronic_disease_report/ (Accessed on 12/05/2013).

[15] Ojofeitimi EO, Adeyeye AO, Fadiora AO, Kuteyi AO, Faborode TG, Adegbenro CA, Bakare OE, Setiloane K, Towobola KS (2007). Awareness of obesity and its health hazard among women in a university community. Pak J Nutr. 6(5):502-505.

[16] Adedoyin RA, Mbada CE, Balogun MO, Tanimola M, Adebayo RA and Akintomide A (2008). Prevalence and Pattern of Hypertension in a Semi-urban Community in Nigeria. Eur J Cardiovasc Prev Rehabil, 15:683-687.

[17] Holdsworth M, Delpeuch F, Landais E, Gartner A, EymardDuvernay S and Maire B (2006). Knowledge of dietary and behaviour-related determinants of non-communicable disease in urban Senegalese women. Public Health Nutr. 9(8):975-981.

[18] Duda R, Kim M, Darko R, Adanu R, Seffah J, Anarfui J and Hill A (2007). Results of the Women's Health Study of Accra: assessment of blood pressure in urban women. Int J Cardiol, 117:115-122.

[19] Centers for Disease Control and Prevention (2000). Unrealized Prevention Opportunities: Reducing the Health and Economic Burden of Chronic Disease. Atlanta, GA: US Department of Health and Human Services, Centers for Disease Control and Prevention.

[20] Halpin HA, Morales-Suárez-Varela MM, Martin-Moreno JM (2010).Chronic disease prevention and the New Public Health. P Health Rev. 32:120-154.

[21] Adedoyin RA, Ibrahim RA, Awotidebe TO, Ativie RN, Oyeyemi AL (2014). Environmental and Socioeconomic Factors Associated with Nigerian University Students' Participation in Physical Activity. International Journal of Sports Science, 4(3): 97-102

[22] Olaoye MO (2004). Research methodology with statistics for health and social sciences. Nathadex publishers, 2nd Edition, 6:115-129. 
[23] Miranda PJ, DeFronzo RAand Califf RM (2005)."Metabolic syndrome: Definition, pathophysiology, and mechanisms," Am. Heart J. 149: 33-45.

[24] Kim S and Popkin BM (2006). Understanding the Epidemiology of Overweight and Obesity - A Real Global Public Health Concern, Commentary. Int J Epidemiol. 35: 60 7.

[25] Lowry R, Wechsler H, Galuska D, Fulton J and Kann L (2002) Television viewing and its associations with overweight, sedentary lifestyle, and insufficient consumption of fruits and vegetables among US high school students: differences by race, ethnicity, and gender. J Sch Health. 72(10): 413-421.

[26] Canadian Hypertension Education Program. 2009 CHEP recommendations for the management of hypertension. 2009. $\mathrm{http}: / /$ hypertension.ca/chep/wp-content/uploads/2009/04/09complete-recs.pdf (Accessed June 18, 2012).

[27] Thompson PD, Buchner D, Piña IL, Balady GJ, Williams MA, Marcus BH, Berra K, Blair SN, Costa F, Franklin B, Fletcher G F, Gordon NF, Pate RR, Rodriguez BL, Yancey AK and Wenger NK (2003).Exercise and Physical Activity in the Prevention and Treatment of Atherosclerotic Cardiovascular Disease. AHA Scientific Statement. A Statement from the Council on Clinical Cardiology (Subcommittee on Exercise, Rehabilitation, and Prevention) and the Council on Nutrition, Physical Activity, and Metabolism (Subcommittee on Physical Activity). Circulation. 107: 3109-3116doi: 10.1161/ 01.CIR.0000075572.40158.77.
[28] Meisler and St Jeor, [33] (1996), Meisler JG and St Jeor S (1996).American Health Foundation - round table on healthy weight. Am J Clin Nutr; 63(Suppl): 409s - 11s.

[29] Davenport T and Prusak L (1998). Working Knowledge. Harvard Business School Press: Boston, MA.

[30] Lynch E, Kiangl L, Kiefe C, Greenland P (2006). CVD risk factor knowledge in young adults and 10year change in risk factors. Am J. Epidemiol. (164): 1171-1179.

[31] Winham DM and Jones KM (2011). Knowledge of young African American adults about heart disease: a cross-sectional survey. BMC Public Health. 11:248. doi: 10.1186/1471-245811-248.

[32] Koebnick C, Smith N, Huang K, Martiez MP Clancy HA, Williams AE and Kushi LH (2012). OBAYA (Obesity and adverse health outcome in young adults). Feasibility of a population-based multiethnic cohort study using electronic medical record. Pop Health Metr, 10:15 doi: 10.1186/14787954-10-15.

[33] Chen, Jr. MS, Kuun P and Guthrie R (1991). Promoting heart health for Southeast Asians: A database for planning interventions. Public Health Reports 106(3): 304-9.

[34] Murphy B, Worcester M, Higgins R, Le Grande M, Larritt P, Goble A (2005). Causal attributions for coronary heart disease among female cardiac patients. J Cardiopulm Rehabil. 25: $135-43$. 